\title{
A NÃO REGULAMENTAÇÃO DO IGF E OS ENTRAVES QUE O RODEIAM: \\ Um estudo sobre o porquê da não normatização dessa espécie tributária
}

\author{
The wealth tax non-regulation and its barriers. \\ A study about that levy non enactment causes
}

\author{
Pilar de Souza e Paula COUTINHO ELOI ${ }^{1}$ \\ Yara Almeida LOPES ${ }^{2}$
}

Artigo recebido em: $12 / 07 / 2016$

Artigo aprovado em: 27/08/2016

RESUMO: Este trabalho busca analisar de forma crítica os motivos que norteiam a não regulamentação do Imposto Sobre Grandes Fortunas. Um imposto que desde sempre ensejou debates fervorosos. O que se vê são interesses pessoais conflitando com interesses coletivos e interferindo em uma economia inteira. Uma das principais vantagens da instituição do Imposto Sobre Grandes Fortunas é a diminuição do desnivelamento social encontrado atualmente no Brasil, onde, em razão de uma política tributária recessiva, os mais pobres arcam com a maior parcela de tributos, ocasionados pela demasiada tributação incidente sobre o consumo e, em contrapartida, uma menor tributação incidente

\footnotetext{
${ }^{1}$ Coordenadora da Pós-Graduação Lato Sensu em Direito Tributário do IEC/PUC Minas. Professora na Graduação e na Pós-Graduação presencial e virtual de Direito Tributário, Econômico e Financeiro da PUC Minas.

Experiência docente também em Direito Administrativo e Direito Processual Civil. Doutoranda em Direito Público (PUC Minas). Mestre em Direito Público em 2014 (PUCMINAS). Pós-graduada em Direito Empresarial (PUCMINAS, 2011). Graduação em Direito pela UFMG (2009). Membra da Comissão em Direito Tributário da OAB-MG. Membra da coordenação do Conselho Editorial da Revista Eletrônica da PUC MINAS Campus Serro. Advogada com atuação em Direito Tributário, Administrativo e Minerário.

E-mail: pilarcoutinhoadv@gmail.com

${ }^{2}$ Graduada em Direito pela PUC-Minas, Pos Graduanda em Direito de Empresa pela PUC-Minas. Advogada. E-mail: yaralopes1@yahoo.com.br
} 
sobre a renda e o patrimônio. É preciso definir, com base em alicerces de uma tributação justa, quem de fato devem ser os contribuintes, quais seriam o fato gerador, as alíquotas e a base de cálculo do referido imposto. E, com base nas experiências internacionais, analisar as dificuldades encontradas no exterior e se elas nos serviriam como parâmetro para adotar a ideia de que realmente precisamos regulamentar o Imposto Sobre Grandes Fortunas ou abandoná-lo de vez.

PALAVRAS-CHAVE: Imposto Sobre Grandes Fortunas; Direito Tributário; Capacidade Contributiva; Justiça Tributária.

ABSTRACT: This work aims to analyze critically the reasons that guide the wealth tax no-regulation. This tax always gave rise to heated debates. Actually, one can see a deep conflict between individual interests against collective ones, which interferes with the whole economy. On one hand, wealth tax institution main advantages might be the Brazilian social inequality reduction. In this country, based on regressive tax policy, the poorest bear the largest taxes share caused by a large consumption levy besides a income and asset smaller taxation. In order to create this tax, it is necessary to review, based on a fair taxation foundation, who actually should be the taxpayers, what is the taxable event, tax rates and bases. These study looks for, based on international experiences and brazilian peculiarities, analyze the difficulties encountered abroad in a effort to decide if this country should create and regulate wealth tax or definitely abandon this burden.

KEYWORDS: Wealth tax; tax law, ability-to-pay principle; tax justice. 


\section{Introdução}

Para que o Estado, como ente soberano, mantenha o funcionamento da própria máquina estatal, precisa de recursos financeiros, e então exige dos seus próprios indivíduos que lhe custeiem por meio dos tributos. Assim, segundo Hugo de Brito Machado (2011), o poder de tributar nada mais é que um aspecto da soberania estatal ou uma parcela desta. A grande e inevitável questão é: quais tributos criar?

O presente trabalho tem como principal viés a discussão acerca da não regulamentação do IGF (Imposto Sobre Grandes Fortunas), que fora introduzido pelo legislador constituinte em 1988, como norma de eficácia limitada, dependendo da regulamentação de norma infraconstitucional pelo constituinte derivado. Passados mais de quinze anos da promulgação da Carta Magna de 1988, a regulamentação ainda não foi realizada, o que traz à tona diversas discussões sobre a viabilidade ou não de sua regulamentação.

Abordar-se-á os principais argumentos daqueles que são pró - dentre os quais, a justiça social e tributária, distribuindo de forma justa a riqueza daqueles que possuem grandes fortunas - e daqueles que são contra - como o desestímulo à produção de riquezas, acarretando até mesmo a punição dos que as detêm.

Dessa forma, em todo o trabalho, a questão discutida passará por diversos ramos do Direito, como o Direito Constitucional, Tributário, Econômico, levando em conta aspectos sociais, socioeconômicos, políticos e fiscais para, ao final, contrabalancear os argumentos e, sendo possível, compartilhar das opiniões contrárias ou favoráveis à instituição do IGF.

\section{As discussões na Assembleia Nacional Constituinte acerca da introdução do IGF e a instituição de uma norma de eficácia limitada}

Antes mesmo de ser instituído em nossa Constituição Federal, o Imposto sobre Grandes Fortunas já ensejava fervorosos debates na Assembleia Nacional Constituinte. É que, segundo os estudiosos do assunto, o tema trazia à tona questões importantes, financeiramente, além das discussões acerca de justiça fiscal.

Não obstante aos fervorosos debates, o constituinte originário introduziu em nossa Carta Magna o referido imposto sem, entretanto, regulamentá-lo, 
deixando isso a cargo do constituinte derivado, que deverá fazê-lo por meio de lei complementar, haja vista a relevância da matéria, já que esta envolve quórum de maioria absoluta para a respectiva aprovação. Passadas décadas da previsão constitucional, a referida lei complementar não foi ainda editada. Quais serão os desafios e as (des)vantagens da regulamentação desse imposto?

\section{Os projetos de lei complementar editados e ainda não votados}

Sabemos que o art. 153, VII, da Constituição Federal se trata de uma norma de eficácia limitada, que aguarda regulamentação desde 1988 quando da promulgação de nossa Carta Magna.

Entretanto, ao longo destes anos, diversos projetos de lei foram editados, com o fito de estabelecer o fato gerador e em que dia do ano ele ocorre, os contribuintes, a definição de grande fortuna, os patrimônios que seriam tributados e os que seriam excluídos da tributação, a base de cálculo, as alíquotas e sua progressividade, a forma de lançamento, os responsáveis, entre outros.

Nesse sentido, Cid Heráclito Queiróz apud Felipe Broering Souza (2014) alerta sobre os motivos pelos quais o constituinte originário estipulou que o IGF fosse criado somente através de lei complementar. Segundo Souza (2014):

[...] muitos detalhes e minúcias deverão ser aplainadas visando facilitar sua aplicação. Seguem algumas delas exemplificadas pelo estudioso acima mencionado: $1^{\circ}$ ) dimensionar e definir grande fortuna; $2^{\circ}$ ) submeter à incidência as pessoas físicas e jurídicas ou somente as físicas; $3^{\circ}$ ) estabelecer método (histórico, de mercado, declarado etc) para a avaliação da fortuna; $4^{\circ}$ ) optar pela progressividade ou proporcionalidade das alíquotas; $5^{\circ}$ ) fixar a real incidência sobre a fortuna ou apenas criar uma espécie de imposto complementar de renda; $6^{\circ}$ ) prescrever a incidência sobre o patrimônio bruto ou líquido; $7^{\circ}$ ) estabelecer a incidência sobre o patrimônio líquido total ou sobre o patrimônio bruto ou líquido imponível, ou seja, excluindo certas classes de bens, como os objetos de uso pessoal (vestuário e mobiliário), o imóvel residencial da família, as obras de valor histórico ou artístico, etc; $8^{\circ}$ ) estabelecer a incidência sobre a simples posse de grande fortuna (estoque) ou apenas no momento de transferência de cada parcela do patrimônio; $9^{\circ}$ ) regular a incidência sobre o patrimônio bruto, líquido ou imponível ou apenas sobre o acréscimo do patrimônio ou somente sobre a mais-valia do patrimônio; $10^{\circ}$ ) prever, ou não, limite conjugado para a incidência dos impostos 
sobre grandes fortunas, ganhos de capital e de renda; $11^{\circ}$ ) estabelecer, ou não, alíquotas diversificadas, segundo a natureza dos bens que integrem o patrimônio (produtivos e improdutivos); $12^{\circ}$ ) negociar e celebrar com outros países acordos para evitar a bi-tributação, particularmente em face dos critérios de incidência, segundo o domicílio do contribuinte ou a situação dos bens (SOUZA, 2014, p. 2-3).

Ademais, embora editados projetos de lei, a regulamentação do referido imposto vai além disso. Há um interesse dos próprios legisladores em jogo, já que boa parte deles se tornaria sujeito passivo daquilo que eles mesmos instituíram. Nesse sentido:

[...] para Amir Khair, mestre em Finanças Públicas e especialista no assunto, o impeditivo que explica a pouca vontade da maioria dos parlamentares é na verdade o próprio perfil econômico do Congresso. "Por que o Congresso não aprova? Porque os congressistas quase sem exceção seriam atingidos por essa tributação. Eles não aprovam nenhuma mudança tributária que os atinja. Essa é a razão central pelo fato de, ao longo de todos esses anos, não ter sido regulamentado o imposto sobre grandes fortunas", opina (IMPOSTOS..., 2003).

Este interesse próprio é um dos indicadores capazes de elucidar o fato de haver tantos projetos já editados e prontos para serem incluídos em pauta, mas que nunca foram arquivados ou mesmo parados.

Dos vários projetos editados, dois ganharam destaque no cenário nacional, o PLP n ${ }^{\circ}$ 202/1989, de autoria de Fernando Henrique Cardoso, e o PLP $n^{\circ} 277 / 2008$ da deputada Luciana Genro, aos quais foram apensados diversos projetos que também versam sobre a normatização do IGF.

Ambos os projetos de lei deixam claro que o objeto principal é a tributação daqueles que detêm grandes fortunas, entretanto, a faixa de tributação e progressividade apresentada pelo projeto de 2008 (uma faixa a mais que o projeto anterior), nos parece mais adequada, assim como a não possibilidade de abatimento daquilo que foi pago a título de IR pelo contribuinte, já que o objetivo do referido imposto é exatamente de tributar mais aquele que possui uma maior capacidade contributiva. 


\section{Uma questão de justiça tributária}

Ao cogitar a criação de um tributo, aquele que o vislumbra deve, além de pensar em sua instituição, ter em mente ideais de justiça, para que esta seja norteadora de tal tributação. Entretanto, a busca por um tributo justo não é fácil, pois nem mesmo a concepção do que é justiça tributária está definitivamente firmada - dependente de percepções morais sobre as origens e causas da desigualdade, da extensão do direito de propriedade e, ainda, do próprio papel do Estado 3 .

Para superar parcialmente a subjetividade, entende-se que a justiça tributária é guiada por princípios tributários, que norteiam atualmente nosso ordenamento - opções positivadas no texto constitucional. Então, para que um tributo atual seja justo, ele não pode contrariar - e, mais que isso, ele deve seguir - a linha dos princípios tributários vértices de nosso ordenamento.

Nesse sentido, segundo Torres (2016), deve-se sempre observar os princípios da capacidade contributiva, da generalidade, da não discriminação e da vedação de privilégios. Os tributos devem ser distribuídos de modo uniforme e, claro, com vistas à proporcionalidade, progressividade e não confisco. Enfim, o tributo legitima-se como justo a partir de quando aplica o inteiro sistema de princípios e regras constitucionais.

O Estado, ao instituir tributos considerados justos, está visando não somente o bem de toda a sua população de um modo geral. Dentro de tal concepção, visa também a redução das desigualdades - objetivo basilar da República Federativa do Brasil (Arts. 3º, III; 43; 151, I; 165, § 6 3 7; 170, VII c/c 192 CF ) . Assim, conforme Murphy e Nagel (2005), para tentar equilibrar uma situação desigual, instituem-se tributos com o fim de aliviar esses problemas.

As maiores controvérsias giram em torno do uso do poder governamental não só para fornecer coisas que são boas para todos, mas também para providenciar recursos para os mais pobres, a partir da ideia de que certas espécies de desigualdade social e eco-

\footnotetext{
${ }^{3}$ A noção de justiça tributária variou segundo as épocas e as formas de tributação. No passado o patrimônio individual e a produção agrícola foram os índices principais de aferição de capacidade econômica e, como justo na Idade Média, predominava o destino das receitas justificado pelo "bem comum"; mais tarde, passou-se para os fatos signos presuntivos de riqueza e para os fatos com a demonstração de capacidade contributiva, tendose a destinação da arrecadação dos tributos dirigida para atender à despesa pública e aos custos dos direitos fundamentais. Como se percebe, a justiça tributária é substantiva, por ser materialmente qualificada segundo certos critérios (TORRES, 2016, p. 217, grifo nosso).
} 
nômica são injustas ou de algum modo maléficas e de que todos nós temos, para com nossos concidadãos, a obrigação de corrigir ou aliviar esses problemas (MURPHY; NAGEL, 2005, p. 233).

Uma vez pontuadas as observações acerca da justiça nos tributos, pode-se começar a analisar se, ao instituir o IGF em nosso sistema jurídico, o constituinte originário teria como um dos fins a concretização da justiça tributária.

Ora, não parece duvidoso que um imposto instituído para tributar aquele patrimônio tão abundante, ao ponto de ser chamado "grande fortuna" (e não apenas fortuna), tenha como um de suas principais finalidades a distribuição das riquezas concentradas nas mãos de poucos e, consequentemente, uma tributação mais justa, que pode aos poucos levar ao equilíbrio das diferenças sociais.

Os direitos de propriedade são direitos que as pessoas têm sobre aquilo que lhes resta depois de cobrados os impostos, e não antes. Isso não quer dizer que não se possa conceber que uma das funções da tributação é tirar dinheiro dos ricos para dar aos pobres, por exemplo. Mas nesse caso, nós não estamos tirando de algumas pessoas algo que pertence a elas; o que ocorre é que o sistema tributário lhes deixa com menos recursos do que teriam sob um sistema menos redistributivo, no qual os ricos ficassem com mais dinheiro à sua própria disposição, ou seja, no qual eles tivessem mais dinheiro (MURPHY, NAGEL, 2005, p. 240).

Até mesmo estudiosos como Francisco José dos Santos, que concluem que a instituição do IGF trará mais prejuízos que benefícios, pontuam acerca dos benefícios que o IGF poderia trazer, alcançando a "verdadeira finalidade dos impostos, qual seja a justiça social, através da redistribuição de riquezas".

O imposto que incide sobre grandes fortunas possuiria como objetivo a prática da justiça social, através da redistribuição da renda proveniente da arrecadação deste imposto. Tal finalidade está inserida nos Atos e Disposições Constitucionais Transitórias em seu art. 80, inciso III, da seguinte forma: “Art. 80. Compõem o Fundo de Combate e Erradicação da Pobreza: [...] III - o produto da arrecadação do imposto de que trata o Art. 153, inciso VII, da Constituição". (...) Por isso o imposto já foi apelidado de "imposto Robin Hood" pelo procurador federal Carlos Vitor Bezerra ${ }^{[101]}$, já que retirará o excesso dos ricos e o distribuirá com os pobres, confirmando então o princípio da capacidade contributiva (COSTA, 2010). 
Assim, à luz de um dos princípios mais importantes da ordem tributária, o legislador, a partir da ideia de capacidade contributiva, busca uma tributação equitativa, na qual quem pode mais contribui com mais, e o produto dessa arrecadação se reverte para a sociedade como um todo e beneficia principalmente aqueles que mais precisam e são excessivamente tributados com impostos que recaem sobre o consumo.

O alcance da justiça tributária tem um importante papel na realização das determinações firmadas no preâmbulo de nossa Magna Carta, que estabelece que o Estado deve assegurar o exercício dos direitos sociais e individuais, a liberdade, a segurança, o bem-estar, o desenvolvimento, a igualdade e a justiça, como valores supremos.

Dessa forma, superado o Estado Liberal, em que o Estado tinha de se abster da vida privada da população, o Estado Social trouxe consigo a segunda geração de direitos, o qual deve garantir sua positivação.

Através dos direitos fundamentais de segunda geração, a proposta que se tem é de um equilíbrio real na relação Estado/cidadão. Fazendo com que, esse ente estatal, que possui o maior poder (econômico, político e jurídico) seja um sujeito, não apenas com direitos, mas com deveres que elevem o cidadão a um status em que possa viver com dignidade, não apenas pelos seus próprios meios, mas também pelos meios ofertados pelo Estado. Assim, dizem respeito aos direitos fundamentais de segunda geração a assistência social, saúde, educação, trabalho, lazer, etc. (MILHOMEM, 2013).

Entretanto, para que consiga consolidar as diretrizes constitucionais, garantindo aos indivíduos seus direitos fundamentais e minimizando as diferenças sociais, o Estado precisa de recursos.

Éaíque, mais uma vez, severifica a importância da instituição de tributos que tenham como fundamento os ideais de justiça tributária, possibilitando, por meio de instrumentos de redistribuição de riquezas, o efetivo gozo dos direitos previstos em nossa Constituição, como indica Alberto Amadei Neto:

Não há como refugar a profunda conexão conceitual vinculante dos direitos humanos fundamentais à fixação do imposto sobre grandes fortunas. $\mathrm{O}$ caudal dos direitos humanos encontra-se concatenado à tributação, tanto que os limites constituintes do poder de tributar não estabeleceram anteparo algum aos privilé- 
gios fiscais - fundados em uma suposta teoria da supremacia do capital perante a cidadania -, mas orientaram para a observância do princípio da capacidade contributiva, em especial das grandes fortunas, sem infirmar direito algum do contribuinte grandemente afortunado, que continua a gozarde isonomia em suas relações equalizadas pelo fisco. A historieta de que o IGF não possui relação alguma com os direitos fundamentais da pessoa humana é o roteiro de um velho conto: a de que o processo de acumulação de riquezas nada tem a ver com a afirmação dos direitos da pessoa humana na vida social (AMADEI NETO, 2012, p.11).

Se os objetivos intrínsecos do IGF partem de ideais essenciais à CF, quais são os entraves à instituição desse tributo?

\section{Dificuldades}

Analisando-se as dificuldades, observa-se que são empecilhos à tributação das grandes fortunas.

\subsection{O desestímulo da aquisição de patrimônio, a punição aos que acumulam patrimônio e a evasão de capitais}

Diversos são os argumentos no sentido de que, ao instituir o IGF, haveria o desestímulo à aquisição de patrimônio. Para Ives Gandra Martins, o imposto seria sentido com mais vigor pela classe média, que não conseguiria dessa tributação escapar. Já os grandes patrimônios seriam desviados para outros países, ou mesmo para pessoas jurídicas. Como consequência, isso desestimularia a poupança.

No mesmo sentido, segundo André Marques, advogado tributarista, o IGF é um desestímulo à acumulação de patrimônio, principalmente se sua alíquota for elevada. Mesmo com a alíquota baixa, não haveria benesse, já que os custos de fiscalização, arrecadação e controle seriam demasiadamente grandes se comparados com os frutos da arrecadação.

Há ainda críticas acerca da incidência de diversos tributos sobre os bens sujeitos ao IGF, o que ocasionaria pluritributações.

Segundo Sabbag (2010) apud Everaldo Maciel, a instituição do IGF "constitui um notável desestímulo à poupança e um peculiar caso de pluritributação, pois tributa mais de uma vez um patrimônio já tributado pelos impostos 
patrimoniais, para não falar da tributação da renda".

Ainda, segundo Sacha Calmon apud Sabbag (2014), criar um tributo sobre as Grandes Fortunas “[...] gera pluritributação. Isto provocaria ainda, uma tremenda evasão fiscal antes mesmo de publicada a lei instituidora".

André Marques ainda aponta o fato de que o imposto fora implementado e logo retirado do ordenamento de diversos países, e diversos contribuintes do imposto na França buscaram cidadania em outros países, como forma de se ver livre de uma carga tributária tão grande sobre o seu patrimônio.

Assim, o governo deveria buscar saber os motivos por que países como Alemanha, Bélgica, Holanda, Itália, Inglaterra e Japão instituíram o IGF e, depois, o abandonaram. [...] foram noticiados casos de milionários e artistas franceses que buscaram cidadania em outros países, porque não se dispunham a entregar para o governo mais de dois terços de suas rendas acima de determinado nível. Casos como estes comprovam que um país não deve instituir tributos sem considerar o padrão mundial, sob pena de ver evadir parte do patrimônio construído em seu próprio território (MARQUES, [20-?]).

Martins (2008) é um dos estudiosos que se mostram extremamente contra a regulamentação do imposto em comento e sintetiza os pontos tratados acima:

Desestimularia a poupança, com efeitos negativos sobre o desenvolvimento econômico; geraria baixa arrecadação, criando mais problemas que soluções (nos países que o adotaram, a média da arrecadação correspondeu de $1 \%$ a $2 \%$ do total dos tributos arrecadados); o controle seria extremamente complexo, com a necessidade de um considerável número de medidas para regulá-lo e fiscalizar a sua aplicação; por fim, poderia gerar fuga de capitais para países em que tal imposição inexiste (a esmagadora maioria não tem o IGF) (MARTINS, 2008).

Completa:

Não sem razão, sabiamente, a esmagadora maioria dos países não o adotou. Os que o adotaram, criaram tantas hipóteses de exclusão que, ao longo do tempo, deixou de ter qualquer relevância. É que o volume da arrecadação termina por não compensar o custo 
operacional de sua administração fiscalização e cobrança. Em outras palavras, é um tributo rejeitado no mundo. Tributar a geração de riquezas, na sua circulação, os rendimentos ou lucros é muito mais coerente e justo do que pretender ainda tributar o resultado final daqueles fatos geradores já incididos (MARTINS, 2008).

Embora haja casos em que a instituição de impostos similares ao IGF não tenha tido êxito em outros países, o Brasil, caso resolva adotá-lo, segundo Carvalho Jr. (2008), “será preciso tempo para aprimora-lo, viabilizando os objetivos maiores de melhorar a distribuição de renda e combater a evasão fiscal".

\subsection{Dificuldades técnicas para a tributação das grandes fortunas}

De certo, para que ainda não tenha sido instituído, há em jogo certos interesses políticos. Entretanto, alguns argumentos de cunho não político são utilizados por estudiosos e autores.

Seguindo essa linha de raciocínio, haveria demasiadas dificuldades para a avaliação dos bens que comporiam a base de cálculo do IGF, já que o lançamento seria feito por declaração do contribuinte, além de uma provável sonegação de bens.

Carvalho Jr. (2008) também acredita que muitos seriam os desafios para a instituição do IGF, tendo em vista a criatividade dos contribuintes para fugir da tributação.

São muitos os desafios político-administrativos do imposto sobre a riqueza. Para fugir da progressividade, o contribuinte pode diluir seu patrimônio entre os contribuintes de sua família ou mesmo criar pessoas jurídicas. Portanto, é necessário ter um cadastro familiar e um cadastro de empresas com a participação das famílias cotistas. Também é preciso ter um sistema avaliatório de bens para confrontar os valores declarados pelos contribuintes, e há necessidade de integrar os sistemas municipais de cadastro e avaliação de imóveis (CARVALHO JÚNIOR, 2008).

Tal entendimento, entretanto, não é compartilhado por Hugo de Brito Machado, que rechaça os argumentos de que haveria dificuldades técnicas para a cobrança do imposto, devido ao seu lançamento por declaração, comparando-o com outras espécies tributárias em plena vigência em nosso ordenamento 
jurídico. ${ }^{4}$ Completa que "ninguém sustentou a inviabilidade do imposto de transmissão causa mortis e doação, de que trata o art. 155, I, nem do imposto de transmissão inter vivos, de que trata o art. 156, II, da CF." (MACHADO, 2010, p. 352).

Ao trazer à tona essas comparações, Machado pretende fazer refletir acerca do que tem de fato por trás dos argumentos de quem aponta essas dificuldades técnicas. O que seria uma dificuldade para levantamento de bens tributáveis, e seus respectivos valores podem estar escondendo um jogo de interesses políticos e de influências.

\subsection{Um jogo de interesses políticos e de influências}

Não é de hoje que os interesses políticos exercem grande influência sobre o sistema tributário, afinal, aqueles que legislam, nossos representantes, acabam por desvirtuar-se do pensamento do bem comum, para proteger os próprios interesses.

Não raros, são os casos de corrupção, em que podemos ver com clareza que o bem coletivo foi suprimido, em detrimento de um anseio pessoal, de aquisição de patrimônios ou qualquer tipo de vantagem que possa ser-lhe oferecida. Por tal motivo, destaca, Machado, que "O verdadeiro motivo da não instituição do imposto sobre grandes fortunas é de ordem política. Os titulares de grandes fortunas, se não estão investidos de poder, possuem inegável influência sobre os que o exercem" (2010, p. 353).

Os titulares da fortuna, então, investidos do poder que lhe é próprio, por meio de sua influência política exercida sobre o poder legislativo ou mesmo em nome próprio, retardam a regulamentação de um imposto em prol de uma ambição própria.

A inclusão do inciso referente a este imposto em nossa constituição se deu em um momento político brasileiro onde podíamos definir correntes contrárias em nosso congresso, o que nos dias atuais é impossível, pois temos hoje uma confusão total entre o que antes chamávamos de esquerda e direita. Este choque de correntes refletia as aspirações de uma gama de anseios sociais os

\footnotetext{
${ }^{4}$ Há quem aponte dificuldades técnicas para a tributação das grandes fortunas. Seriam problemáticas a identificação e a avaliação dos bens. O argumento é inconsistente. Os bens que integram as grandes fortunas são os mesmos cuja a transmissão da propriedade é tributada. Se a título oneroso, pelo Município. Se a título gratuito, ou em virtude de sucessão por causa da morte, pelo Estado (MACHADO, 2010, p. 352).
} 
quais foram refletidas fortemente em nosso ordenamento jurídico. No momento atual há uma maior dificuldade de inclusão do estudado instituto pela dificuldade de que ocorram fortes choques legislativos que contrariem os interesses das classes mais abastadas, mesmo com a determinação constitucional de que se faça tal inovação jurídica. Outro grave problema é encontrado no descaso do legislador constituinte em delegar excesso de poderes ao legislador complementar para definições inerentes ao IGF, o que vem a se chocar com as características do sistema tributário pátrio (SOUZA apud INFORZATO, 2013).

Os próprios presidentes do Brasil, dentre os quais se identifica o proponente de um relevante projeto de lei acerca do IGF, antes de ocuparem o posto de presidente da República, trataram por engavetar o projeto, ficando claro o jogo de influências que norteia a regulamentação de tal espécie tributária, como é retratado abaixo:

Assim, tratou-se de eliminar esse instrumento fiscal capaz de mitigar a concentração social da riqueza. Os presidentes Fernando Henrique, Lula da Silva e Dilma Rousseff abandonaram o IGF. O secretário-executivo do Ministério da Fazenda, responsável pela questão tributária, afirmou na audiência pública do Parlamento, em maio de 2011, que um "imposto sobre grandes fortunas não é intenção do governo". O que isso significa? O governo fica a favor da "não tributação" das grandes fortunas, com suporte de ex-secretários da Receita Federal consultores e ex-ministros da Fazenda banqueiros. O caso mais bem-sucedido é o terrorismo fiscal contra a transformação do IGF em Contribuição Social vinculada à saúde. Os muito ricos transformaram o IGF numa espécie de "efeito estufa', fator de alto risco, ameaçador do "enriquecimento global", de tal modo que a proteção das fortunas grandes tornou-se equivalente à garantia do "meio ambiente econômico": O que poderia ser maior do que "salvar o meio ambiente?" (AMADEI NETO, 2012, p. 9).

O Senado Federal divulgou em 2015 um estudo acerca do IGF, no qual expõe que existem algumas propostas de Emenda à Constituição, no que tange ao IGF, dentre elas, a PEC 45/2007, que propõe surpreendentemente (ou não) a revogação do IGF, tendo como argumento a fuga de capitais a ser gerada por sua instituição, e a baixa arrecadação. 


\section{O porquê da instituição do IGF - argumentos favoráveis}

A principal tese para a instituição do IGF está ligada à justiça fiscal que se visa obter por meio da redistribuição de riquezas, ligada sempre ao princípio da capacidade contributiva e da igualdade. Além do mais, sua instituição se liga à ideia de que seria um estímulo à utilização produtiva do patrimônio, para que possa gerar renda, etc.

\subsection{Promoção da justiça fiscal. Redistribuição de riquezas}

O alcance da justiça fiscal ajuda na promoção dos direitos sociais garantidos em nossa Constituição, como a igualdade e a dignidade da pessoa humana. Assim, por meio de instrumentos de redistribuição de riquezas, como a instituição do IGF, o Estado consegue garantir à sua população os direitos fundamentais.

É pelos motivos mencionados acima, que o IGF ganha preciosos argumentos favoráveis à sua instituição. Em sociedades atuais, deve-se primar pelo bem coletivo, e, para o alcance de tal, é preciso que haja uma contribuição mútua. Em uma sociedade democrática, assim como o Brasil, se deve primar pelo equilíbrio social da população.

Nesse sentido, segundo Khair (2015):

Talvez a Constituição represente uma regra de convívio social na qual a população de menor renda tenha um pouco mais de acesso aos bens de democracia. A democracia prevê um regime de maior equilíbrio social. Prevê um regime do governo para o povo, de interesse do povo. Quando você estabelece na Constituição um imposto sobre grandes fortunas, que no fundo, independente do nome, é um imposto que visa alcançar riqueza, você está contribuindo para uma melhor distribuição dela entre a população. Esse foi o objetivo dos constituintes em 1988. O que não se esperava é que o próprio Congresso que aprovou isso seja o Congresso a não aprovar a regulamentação desse tributo. E a razão é muito simples. Por que o Congresso não aprova? Porque os congressistas quase sem exceção seriam atingidos por essa tributação. Quando eles são atingidos, eles não aprovam nenhuma mudança tributária que os atinja. Essa é a razão central pelo fato de, ao longo de todos esses anos, não ter sido regulamento o imposto (KHAIR, 2015). 
As grandes riquezas concentradas em poucas mãos não trazem benefícios coletivos, gerando apenas satisfações individuais, e, por isso, se faz necessária, a redistribuição, fornecendo, ao Estado, meios de promover a minimização das desigualdades e garantir que a dignidade da pessoa humana seja sempre respeitada.

\subsection{Potencialidade de arrecadação}

Há quem aponte que a quantidade reduzida de contribuintes seja um empecilho para a instituição de IGF, e que o pequeno número de contribuintes, e, consequentemente, de arrecadação não valeria o investimento na implementação e fiscalização do IGF. Entretanto, há mais de uma forma de se olhar a mesma situação.

A quantidade reduzida de contribuintes acaba por corroborar a fiscalização e cobrança desse tributo, já que o fisco não precisará criar um sistema que abrangerá a maior parte da população do Brasil, mas a menor parte dela.

Outros impostos, com número muito maior de contribuintes, foram instituídos e funcionam, há algum tempo, no Brasil, sem que houvesse dificuldades impossíveis de serem ultrapassadas. E isso, muito menos, ocorreria com um imposto cujo número de contribuintes é restrito.

Segundo Amir Kair (2015), mestre em finanças públicas, "é preciso isentar uma parcela da população. Com patrimônios de cerca de um milhão de reis você já tira dessa tributação $95 \%$ ou $98 \%$ da população brasileira". Entretanto, completa, Amir que, ainda assim, é possível se obter um excelente resultado dessa tributação de $2 \%$ ou $5 \%$ da população.

Em estudo sobre o tema, Amir Khair (2008) mostra a potencialidade de arrecadação do IGF. Tendo-se por base uma alíquota de 1\%, poder-se-ia ter arrecadado cerca de $\mathrm{R} \$$ 18,5 bilhões, em 1999 (1,73\% do PIB), e R \$ 22,3 bilhões, em 2000 (1,89\% do PIB), superando o valor correspondente à arrecadação da CPMF $0,75 \%$ e $1,22 \%$, respectivamente.

\subsection{Combate da evasão fiscal através do cruzamento de cadastros, dados e informações tributárias}

Um outro ponto visto como dificuldade é o que concerne à evasão fiscal, pela qual os contribuintes fariam uso de meios ilícitas para se eximir da 
responsabilidade de pagar o tributo.

Entretanto, tem ficado cada vez mais difícil burlar o sistema criado pela Receita Federal do Brasil, que tem vários instrumentos capazes de cruzar informações e verificar se o que fora declarado pelo contribuinte está de acordo com as demais informações passadas por ele e por suas demais movimentações financeiras.

Não obstante, pode-se comparar a declaração do IR e a declaração do IGF, que também seria alvo de controle da SRFB. Nesse sentido, a Receita Federal vem mostrando que, a cada dia, está mais efetiva, no que diz respeito à rastreabilidade das informações que são passadas pelos contribuintes, sejam eles pessoas físicas ou jurídicas, por meio de suas declarações.

Daí, se falar do efeito extrafiscal que o IGF poderia ocasionar, já que, como mais uma fonte de dados a serem enviadas ao fisco, as declarações do IR deveriam necessariamente não discrepar do que foi apresentado na declaração do IGF, e vice e versa.

\subsection{A necessidade de se tributar melhor}

Um dos grandes problemas enfrentados no sistema tributário brasileiro gira em torno dos tributos que incidem sobre o consumo, onerando demasiadamente aqueles que detêm menos recursos financeiros e, superficialmente, aqueles que têm maior capacidade contributiva.

Esse sistema tributário fomenta a desigualdade já instalada no Brasil, sustentando a concentração de renda nas mãos de poucos, com a baixa incidência dos impostos sobre o consumo, e fazendo com que aqueles que pouco têm, devam contribuir com mais.

Assim, sendo inviável a adoção de uma tributação sobre o consumo que tribute de acordo com a capacidade contributiva, embora já sejam norteados pela seletividade, por que não direcionar a maior parte dos tributos para o patrimônio e a renda, que possibilitam a progressividade, por exemplo? ${ }^{5}$

\footnotetext{
${ }^{5}$ Há varias doutrinas justificativas da progressividade, umas de caráter politico e moral, outras fundadas em teorias econômicas. Entre as primeiras sobreleva a "compensatória", que atribui ao Estado o dever de corrigir as desigualdades que ele engendrou [...], ou não evitou [...]. Outros discutem se a tributação se fundamenta no "benefício" recebido pelos contribuintes, ou no dever do "sacrifício igual", na medida da capacidade contributiva (abillity to pay) de cada um deles. A orientação moderna voltou-se para esta ultima teoria, que tem como consequência a progressividade. Mas os próprios defensores da teoria do benefício sustentavam a necessidade de isentar-se o "mínimo de existência" ou "necessário físico" do contribuinte, política que, praticamente, realiza uma das técnicas de imposto degressivo sobre a totalidade da renda (BALEEIRO, 1998, p. 219).
} 
Tal disparidade pode ser corrigida aliviando a carga tributária incidente sobre o consumo e transferindo parte dela para tributar o patrimônio e a renda, observando sempre os princípios da igualdade e da capacidade contributiva. Daí a importância de se normatizar o IGF.

\section{Conclusão}

Que o Brasil precisa passar por uma reforma tributária, é cediço. É preciso tributar menos o consumo e retirar a sobrecarga sentida por aqueles que dispõem de menos recursos, tributando mais aqueles que podem mais contribuir.

O Brasil precisa redistribuir as riquezas concentradas em poucas mãos, diminuindo, assim, o problema tão grande de desigualdade e seus impactos sobre a coesão social e a construção da cidadania, que nos trazem índices tão negativos, quando comparados a diversos países do mundo. No entanto, para que se possa atingir tais objetivos, é preciso combater problemas internos, dentre cujas soluções, deve-se realizar uma revisão profunda do sistema tributário nacional. Uma revisão que pense na totalidade do ônus do Estado, nos objetivos da República e na divisão do ônus tributário entre os diversos membros da sociedade.

São objetivos quase românticos diante de uma sociedade em que o interesse próprio, a vontade de defender e proteger somente o que é seu, a vontade de não ver o próprio patrimônio tributado, mesmo que seja em prol do país, e mesmo que não lhe cause confisco de patrimônio, prevalecem. É esse contexto que enseja uma reflexão sobre o cabimento da instituição do IGF.

Existem de fato argumentos técnicos para a não regulamentação do IGF, mas há também a prevalência de interesses políticos de classes que, embora tenham o poder de lutar em prol daquilo que elas próprias representam - seu país -, deixam-se levar por interesses individuais e daqueles que lhes convêm.

A instituição do IGF se faz necessária no Brasil, como abordamos diversas vezes no decorrer deste trabalho, por uma questão de justiça tributária, que se perfaz em ideais de justiça social.

O caráter extrafiscal dessa espécie tributária supera seu caráter fiscal arrecadatório. O estímulo à destinação produtiva do patrimônio, o caráter complementar ao imposto de renda, no que tange à dificuldade que seria criada para se livrar de tal imposto, e, principalmente, o nivelamento social, que poderia ao longo do tempo estimular, no Brasil, ou, ao menos, minimizar tamanha desigualdade que vivemos hoje. 
No entanto, para que se consiga um imposto justo, é preciso que sejam levadas em conta experiências internacionais, sem, contudo, deixar que os casos de infortuna sirvam como desestímulo, mas como aprendizagem. É preciso que se faça como na maioria dos projetos apresentados, a utilização de institutos tão importantes no direito tributário, como a progressividade.

É preciso que, na regulamentação do Imposto Sobre Grandes Fortunas, o instituto da progressividade venha acompanhado de alíquotas justas que não atinjam um patamar confiscatório, alinhada a uma base de cálculo que tribute não apenas a fortuna, mas a grande fortuna, como quis o legislador constituinte.

A construção de um projeto com alíquotas, fato gerador, base de cálculo e contribuintes, que respeite aquilo que o constituinte originário propôs, leva-nos a um dos temas em que se encontram mais controvérsias: a questão da justiça.

E, se estamos falando em uma tributação justa, não é válido que se tribute indiscriminadamente, ao ponto de atingir aqueles que detêm fortunas, mas não grandes fortunas. Assim, estar-se-ia sendo injusto com a parcela que não deveria ser contribuinte e mais injusto ao não tributar aqueles que devem ser sujeitos passivos.

Entretanto, essa é apenas uma fração do que pode significar justiça. Conforme tratado anteriormente, a questão da justiça é controversa, e nem mesmo sua definição está definitivamente firmada, em razão de seu grau de subjetividade.

Assim, para que, ao menos um tributo, se guie pela ideia de justiça, e já que o conceito do que é justo não é algo cediço, em razão da subjetividade que o rodeia, é preciso que seja norteado pelos princípios e regras constitucionais e tributárias.

A política tributária no Brasil não favorece a instituição do Imposto Sobre as Grandes Fortunas, já que temos um sistema de tributação, principalmente, voltado para o consumo e, minimamente, voltado para o patrimônio, o que se perfaz em uma necessidade de reforma tributária nacional.

Finalmente, analisados os prós e contras da possível regulamentação do IGF, um imposto que, desde as discussões iniciais, já ensejou debates acirrados, embora as dificuldades que de fato irão rodear sua implementação não serão maiores que os benefícios trazidos por ela.

Assim, tomando por base todo o estudo realizado, é possível acreditar que a regulamentação do IGF deva de fato ocorrer e que ideais políticos e interesses próprios contribuíram decisivamente para que sua implementação, 
mais de duas décadas depois da promulgação de nossa Constituição Federal, não tenha ocorrido.

\section{Referências}

ALBUQUERQUE, Raíssa Carvalho Fonseca e. Da omissão legislativa na instituição do Imposto sobre Grandes Fortunas. In: Âmbito Jurídico, Rio Grande, XVII, n. 122, mar 2014. Disponível em: <http://www.ambitojuridico.com.br/site/?n_link=revista_artigos_leitura\&artigo_id=14578\&revista_caderno =2 6>. Acesso em maio 2016.

ALBUQUERQUE, Raíssa Carvalho da Fonseca e. Da omissão legislativa na Instituição do Imposto Sobre Grandes Fortunas. Fev. 2014. Conteúdo Jurídico. Disponível em: <http:/ / www.conteudojuridico.com.br/artigo,da-omissa o-legislativa-na-instituicao-do-imposto-sobre-grandes-fortunas,47163.html>. Acesso em: 03 maio 2016.

AMADEI NETO, Alberto. Imposto sobre grandes fortunas. In: CATTANI, Antonio David; OLIVEIRA, Marcelo Ramos (orgs.). A sociedade justa e seus inimigos. Porto Alegre: Tomo Editorial, 2012, p. 149.

ATHENIENSE, Aristóteles Dutra de Araújo. O Imposto Sobre Grandes Fortunas. [20--?]. Aristóteles Atheniense Advogados. Disponível em: <http://www.atheniense.com.br/artigos/o-imposto-sobre-grandes-fortunas/>. Acesso em 20 de maio de 2016.

BAGGIO, Gabriel. Bitributação. Jun. 2015. Jusbrasil. Disponível em: <http://luizgabrielbaggio.jusbrasil.com.br/artigos/149297469/bitributacao>. Acesso em: 29 mar. 2016.

BALEEIRO, Aliomar. Uma introdução a Ciências das Finanças. 15. ed. Rio de Janeiro: Forense, 1998, p. 219-224.

BASTOS, Roseli Quaresma. Elisão e evasão fiscal: Os limites do planejamento tributário. In Âmbito Jurídico, Rio Grande, XIII, n. 81, out 2010. Disponível em: <http:/ / www.ambito-juridico.com.br/site/index.phpn_link=revista_artigos_leit ur a\&artigo_id=8325>. Acesso em 20 abr. 2016.

BATISTA, Juarez Marques. Projeto de Lei $\mathbf{n}^{0} 108$, de 1989. Institui o Imposto sobre Grandes Fortunas, de que trata o inciso VII, do art.153 da Constituição e dá ou- 
tras providências. Disponível em: <http://www.camara.gov.br/proposicoesWeb/ fichadetramitacao?idProposicao=21475> . Acesso em 29 mar. 2016.

BRASIL. Constituição (1988). Constituição da República Federativa do Brasil. Brasília: Senado, 1988.

BRASIL. Lei ${ }^{0} 5.172$ de 25 de outubro de 1966. Dispõe sobre o Sistema Tributário Nacional e institui normas gerais de direito tributário aplicáveis à União, Estados e Municípios. Diário Oficial da União, Brasília 25 out. 1966.

CARDOSO, Fernando Henrique. Projeto de Lei $\mathbf{n}^{0}$ 202, de 1989. Dispõe sobre a tributação de grandes fortunas, nos termos do art. 153, inciso VII da Constituição. Disponível em: <http://www.camara.gov.br/proposicoesWeb/fichadetramitacao?idProposicao=21594>. Acesso em: 29 mar. 2016.

CARVALHO JÚNIOR, Pedro Humberto Bruno de. As discussões sobre a regulamentação do Imposto sobre Grandes Fortunas: a situação no Brasil e a experiência internacional. Rio de Janeiro: IPEA, 2011. (Nota Técnica). Disponível em: <http:/ / www.ipea.gov.br/agencia/images/stories/PDFs/nota_tecnica/111230_notatecnicadinte7.pdf>. Acesso em: 26 maio 2016.

CARVALHO JÚNIOR, Pedro Humberto de. Imposto Sobre Grandes Fortunas. IPEA Desafios do desenvolvimento, v. 5, n. 43, 2008. Disponível em: <http://www.ipea. gov.br/desafios/index.php?option=com_conte $n$ t\&id=977:catid=28\&Itemid=23>. Acesso em: 23 maio 2016.

CONSELHO Regional de Contabilidade de Santa Catarina. Receita cruza dados e pega sonegadores. Jusbrasil, 2012. Disponível em: <http://crc-sc .jusbrasil.com.br/ noticias/3079479/receita-cruza-dados-e-pega-sonegadores>. Acesso em: 06 maio 2016.

CORSATTO, Olavo Nery. Imposto Sobre Grandes Fortunas. Revista de informações legislativas, Brasília, v. 5, n. 146, 2000. Disponível em: <http:/ /www2.senado. leg.br/bdsf/bitstream/handle/id/581/r146-06.pdf?seq ue n ce=4>. Acesso em: 07 maio 2016.

COSTA, Francisco José Santos da. Imposto Sobre Grandes Fortunas: um estudo crítico. Imposto Sobre Grandes Fortunas em uma abordagem comparada. Out. 2010. Jus Navigandi. Disponível em: <https://jus.com.br/artigos/17656/imposto-sobregrandes-fortunas-um-estudo-critico/3>. Acesso em 10 maio 2016. 
FERNANDES, Bernardo Gonçalves. Curso de Direito Constitucional. 3. ed. Belo Horizonte: Lumen Juris, 2011, p. 78-88.

FERRAZ, Luciano; GODOI, Marciano Seabra de; SPAGNOL, Welter Botelho. Curso de Direito Financeiro e Tributário. Belo Horizonte: Fórum, 2014, p. 21, 26, 179.

GENRO, Luciana. Projeto de Lei 277, 2008. Regulamenta o inciso VII do art. 153 da Constituição Federal (Imposto sobre Grandes Fortunas). Disponível em: <http:/ / www.camara.gov.br/proposicoesWeb/fichadetramitacao?idProposi cao= 388149>.

GÓES, José Cristian. Impostos: quanto mais se ganha, menos se paga. Set. 2011. Infonet. Disponível em <http://www.infonet.com.br/josecristiangoes/ler.asp?id=118116>. Acesso em: 02 abr. 2016.

IMPOSTO Sobre Grandes Fortunas aguarda votação há 15 anos. Out 2003. Sindifisco. Disponível em: <http://www.sindifisco.org.br/noticias/imposto-sobre-fortunas-aguarda-votacao-ha-15-anos>. Acesso em: 04 maio 2016.

INFORZATO, Maria Clara. Vantagens e Desvantagens do Imposto Sobre Grandes Fortunas. Maio 2013. Jurisway Disponível em <http:/ / www.jurisw ay.org.br/v2/ dhall.asp?id_dh=10755>. Acesso em: 02 abr. 2016.

KHAIR, Amir. Imposto sobre grandes fortunas renderia 100 bilhões por ano. Carta Capital, 03 mar. 2015. Entrevista concedida a Renan Truffi. Disponível em: <http:/ / www.cartacapital.com.br/economia/imposto-sobre-grandes-fortunas-renderia100-bilhoes-por-ano-1096.html>. Acesso em: 06 de maio de 2016.

LEITÃO, Cláudio Sá; FELDMAN, Bruno. Tributação sobre distribuição de lucros. 11 mar. 2016. Diário de Pernambuco. Disponível em: <http:/ / www.diariodepernambuco.com.br/app/noticia/opiniao/46,97,43,74/2016/03/11/interna_o piniao,139643/ tributacao-sobre-distribuicao-de-lucros.shtml>. Acesso em: 07 maio 2016.

MACHADO, Hugo de Brito. Curso de Direito Tributário. 31. ed. São Paulo: Malheiros, 2010, p. 352-353.

MARIZ, Antônio. Projeto de Lei ${ }^{\circ}$ 208, de 1989. Regulamenta o art. 153, inciso VII, da Constituição Federal, que dispõe sobre o imposto das grandes fortunas. Disponível em: <http://www.camara.gov.br/proposicoesWeb/fichadetramitacao?idProposicao=21597>. Acesso em 29 mar. 2016. 
MARQUES, André. Grandes fortunas e o debate sobre a má distribuição da renda no Brasil. SINDAF, Goiânia, 2016. Disponível em: <http:/ / www.sindafgo .com.br/ noticiaInd.php?id=527>. Acesso em: 08 de maio 2016.

MARTINS, Ives Gandra da Silva. O Imposto Sobre Grandes Fortunas. Fev. 2008. Jusnavigandi. Disponível em: <https://jus.com.br/artigos/10977/o-imposto-sobre-grandes-fortunas>. Acesso em: 29 mar. 2016.

MENDES, Gilmar. Jurisdição Constitucional no Brasil: o problema da omissão legislativa inconstitucional. Maio 2008. STF. Disponível em: <http://www.stf.jus.br/ arquivo/cms/noticiaArtigoDiscurso/anexo/Lituania.pdf>. Acesso em: 15 abr. 2016.

MICHAELIS. Grande. In: MICHAELIS. Dicionário de Português Online. [S.l.]: Melhoramentos, 2009. Disponível em: <http://michaelis.uol.com.br/moderno/portugues/definicao/grande\%20_974039.html>. Acesso em: 08 de maio 2016.

MICHAELIS. Fortuna. In: MICHAELIS. Dicionário de Português Online. [S.1.]: Melhoramentos, 2009. Disponível em: <http://michaelis.uol.com.br/moderno/portugues/index.php?lingua=portugues-portugues\&palavra=fortuna $>$. Acesso em: 08 de maio 2016.

MILHOMEM, Brenno de Paula. Direitos de primeira e segunda geração no Estado Democrático de Direito. Fev. 2013. Jurisway. Disponível em: <http:// www.jurisway.org.br/v2/dhall.asp?id_dh=10104>. Acesso em: 28 abr. 2016;

MURPHY, Liam; NAGEL Thomas. O mito da propriedade. Marcelo Brandão Cipolla (tradução). São Paulo: Martins Fontes, 2005 p. 233-240.

SABBAG, Eduardo. Manual de Direito Tributário. 6. ed. São Paulo: Saraiva, 2014.

SHOUERI, Luís Eduardo. Direito Tributário. São Paulo: Saraiva, 2015, p.388-395.

SILVA JÚNIOR, Valter Peixoto da. A viabilidade da regulamentação do Imposto Sobre Grandes Frtunas (IGF). Jul. 2015. Jus Navigandi. Disponível em<https://jus. com.br/artigos/41021/a-viabilidade-da-regulamentacao-do-imposto-sobre-grandes-fortunas-igf>. Acesso em: 22 abr. 2016;

SILVA JÚNIOR, Valter Peixoto da. A viabilidade da regulamentação do Imposto Sobre Grandes Fortunas (IGF). Ago. 2015. Jusbrasil. Disponível em: < http:/ / valter- 
jr3.jusbrasil.com.br/artigos/209437181/a-viabilidade-da-regulame ntacao-do-imposto-sobre-grandes-fortunas-igf>. Acesso em 22 abr. 2016.

SILVA, Jules Michelet Pereira Queiroz e; ARAÚJO, José Evande Carvalho. Medidas Antilesivas na Instituição e Cobrança do Imposto Sobre Grandes Fortunas (IGF). Brasília: Câmara dos Deputados, 2015. Disponível em: <http://www2.camara.leg.br/documentos-e-pesquisa/publicacoes/est nottec/ ar eas-da-conle/ tema20/2015_165_imposto-grandes-fortunas_-jose-evande-e-car valho-araujo $>$. Acesso em: 08 maio 2016.

SOUZA, Felipe Broering de. Imposto Sobre Grandes Fortunas: Projeto de Lei apresentados e casos internacionais similares. Revista de Finanças Públicas: Tributação e Desenvolvimento, v. 2, n. 2, 2014. Disponível em: <http://www.e-publicacoes. uerj.br/index.php/rfptd/article/view/11420/10134>. Acesso em: 10 maio 2016.

TRUFFI, Renan. Imposto Sobre Grandes Fortunas renderia 100 bilhões por ano: Especialista estima que a taxação de patrimônios acima de um milhão de reais poderia render um valor equivalente ao da extinta CPMF. Mar. 2015. Carta Capital. Disponível em <http://www.cartacapital.com.br/econo mia/im posto-sobre-grandes-fortunas-rend eria-100-bilhoes-por-ano-1096.html>Acesso em: 19 abr. 2016;

TORRES, Heleno Taveira. A Justiça dos Tributos. In: DERZI, Misabel Abreu Machado; MELO, João Paulo Fanucchi de Almeida (coord.). Justiça Fiscal. Belo Horizonte: Del Rey, 2016. Cap. 10, p. 217-253. 